\title{
Parâmetros de Fermentação e Medidas Morfométricas dos Compartimentos Ruminais de Bezerros Leiteiros Suplementados com Milho Processado (Floculado vs. Laminado a Vapor) e Monensina ${ }^{1}$
}

\section{Carla Maris Bittar Nussio*2, Flávio Augusto Portela Santos ${ }^{3}$, Maity Zopollatto ${ }^{4}$, Alexandre Vaz Pires $^{3}$, Janice Barreto de Morais ${ }^{4}$, Juliano José de Resende Fernandes ${ }^{4}$}

\begin{abstract}
RESUMO - O objetivo deste trabalho foi avaliar as alterações do fornecimento de grãos processados (laminado a vapor vs. floculado) e monensina em parâmetros ruminais. Dezesseis bezerros holandeses foram fistulados no rúmen com 3-5 dias de vida e agrupados em blocos ao acaso, com arranjo fatorial 2 × 2. Os animais receberam concentrado ad libitum até o consumo de $2 \mathrm{~kg} / \mathrm{d}, 4$ litros diários de leite e tiveram acesso livre à água. Após a desmama, realizada na oitava semana de vida, os animais passaram a receber $2 \mathrm{~kg} / \mathrm{d}$ de concentrado e feno de coastcross picado ad libitum. Os tratamentos não afetaram o consumo de concentrado e feno, assim como o desempenho animal, os quais foram inferiores ao esperado. A concentração molar de propionato foi maior para animais recebendo grão laminado. Houve tendência de maior concentração molar de $\mathrm{AGV}$ total $(\mathrm{P}=0,11)$ e butirato $(\mathrm{P}=0,13)$ para animais recebendo grão laminado. A inclusão de monensina tendeu a reduzir as concentrações de $\mathrm{N}_{-} \mathrm{NH}_{3}$ ruminal $(\mathrm{P}=0,12)$. O peso do retículo-rúmen $(\%$ trato total) tendeu $(\mathrm{P}=0,09)$ a ser maior em animais recebendo grão laminado e monensina. A capacidade do retículo-rúmen foi aumentada pelo fornecimento de grão laminado e monensina. Milho floculado resultou em maior peso do abomaso em \% trato total.
\end{abstract}

Palavras-chave: ácidos graxos voláteis, amônia ruminal, ionóforo

\section{Ruminal Fermentation Parameters and Metric Measurements of the Rumen of Dairy Calves Fed Processed Corn (Steam-Rolled vs. Steam-Flaked) and Monensin}

\begin{abstract}
The objective of this study was the evaluation of the effects of grain processing (steam-rolled vs. steam-flaked) and monensin on ruminal parameters. Sixteen Holstein calves were ruminally canulated with 3 to 5 days of life, and utilized on a completely randomized design block with a 2 x 2 factorial arrangement. The animals received concentrate ad libitum up to $2 \mathrm{~kg} / \mathrm{d}, \mathrm{plus} 4 \mathrm{~L} / \mathrm{d}$ of milk. Calves had free access to water. After weaning at the eight weeks of life, calves received concentrate and chopped hay. Animal performance, concentrate and hay intakes were lower than expected and not affected by treatments. The molar proportion of propionate was higher for steam-rolled concentrate. There was a tendency for higher total VFA $(\mathrm{P}=.11)$ and butyrate $(\mathrm{P}=.13)$ for steam-rolled corn. Monensin tended to reduce ruminal $\mathrm{N}-\mathrm{NH}_{3}$ concentration $(\mathrm{P}=.12)$. Weight of reticulum-rumen $($ as $\%$ total tract $)$ tended $(\mathrm{P}=.09)$ to be higher for calves on steam-rolled and monensin concentration. However, the capacity of reticulum-rumen was increased by steam-rolled and monensin feeding. Steam-flaked concentrate resulted on heavier abomasum, as \% total tract.
\end{abstract}

Key Words: ionophore, ruminal ammonia, volatile fatty acids

\section{Introdução}

O alto custo de produção de bezerros leiteiros, principalmente na fase de aleitamento, tem levado à busca de ferramentas de manejo que permitam a desmama precoce. Entretanto, a desmama só é realizada de maneira adequada, sem prejuízos ao desempenho animal, quando este apresenta o rúmen ao menos parcialmente desenvolvido, capaz de assumir uma dieta de ruminante (Quigley, 1996b).
O desenvolvimento de bezerros recém-nascidos à condição de ruminante funcional envolve uma série de mudanças anatômicas e fisiológicas no seu aparelho digestivo (Beharka et al., 1998). Embora o desenvolvimento do aparelho digestivo desses animais seja inato, a idade do animal per se tem pouco efeito.

Ao nascer, estes animais apresentam o retículorúmen pouco desenvolvido e não funcional, representando apenas $30 \%$ do total dos quatro compartimentos. As maiores mudanças em termos de desenvolvimento

\footnotetext{
${ }^{1}$ Parte da tese de Doutorado em Ciência Animal e Pastagens apresentada pelo primeiro autor à USP/ESALQ. Projeto financiado pela FAPESP.

2 Bolsista FAPESP. Pesquisadora Embrapa Pecuária Sudeste. E.mail: carla@cppse.embraba.br

3 Prof. Dr. Depto. de Produção Animal - USP/ESALQ, C.P.09 - CEP: 13418-900 - Piracicaba, SP. E.mail: fapsanto@esalq.usp.br; alvpires@esalq.usp.br

${ }^{4}$ Aluno de Pós-graduação em Ciência Animal e Pastagem - USP/ESALQ. E.mail: mzopolla@esalq.usp.br; jbmorais@esalq.usp.br; jjrfern@esalq.usp.br
} 
vão ocorrer no retículo-rúmen, o qual será colonizado por diferentes tipos de microrganismos e terá sua musculatura e parede interna (papilas) desenvolvidas, como também enzimas funcionais na parede do rúmen. Por volta de 3 a 4 semanas, dependendo da alimentação do animal, o retículo-rúmen passa a corresponder a $60 \%$ do total dos quatro compartimentos, enquanto o abomaso, somente a $27 \%$. Um animal com mais de 12 semanas de vida apresenta o sistema digestivo próprio de um ruminante, sendo o retículo-rúmen $85 \%$ e o abomaso apenas $7 \%$ do total dos quatro compartimentos (Huber, 1969).

Muitos trabalhos têm mostrado que o desenvolvimento de papilas, responsáveis pela absorção de produtos finais de fermentação, é dependente da presença de ácidos graxos voláteis (Tamate et al., 1962; Murdock \& Wallenius, 1980; Quigley et al., 1996a). Dentre os principais AGV produzidos no rúmen, o ácido butírico é o mais importante em relação ao crescimento em número e tamanho de papilas, seguido pelo ácido propiônico; tendo o ácido acético pouca importância. A maior produção desses ácidos graxos voláteis ocorre com a fermentação de alimentos concentrados, com alto teor de carboidratos e proteína. Assim, a disponibilidade de concentrado para o animal desde a primeira semana de vida é indispensável (Anderson et al., 1987).

O consumo de grãos processados, como floculado ou laminado, altera o padrão de fermentação ruminal de forma benéfica ao animal, com maior produção de propionato e conseqüente maior produção de glicose através da gluconeogênese (Theurer et al., 1999). A adição de grão floculado em dietas de animais de corte em crescimento ou engorda tem mostrado consistente aumento na eficiência alimentar, quando se fornece maior quantidade de amido, em comparação ao grão não processado ou laminado (Theurer et al., 1996).

Dados de desempenho de bezerros em aleitamento recebendo grão processado na mistura concentrada são restritos. Schuh et al. (1970) e Daniels et al. (1972) não observaram efeitos positivos no desempenho ou consumo de concentrado com a inclusão de grãos processados no concentrado de bezerros. Em trabalho subseqüente, Schuh et al. (1971) observaram maiores ganho de peso diários e consumo de MS em animais recebendo grão floculado. Abdelgadir \& Morrill (1995) compararam concentrado contendo sorgo não processado, tostado ou conglomerado para bezerros em aleitamento. O tipo de processamento não afetou o desempenho, as medidas corporais ou a idade a desmama dos animais, assim como parâmetros sanguíneos ou ruminais; entretanto, os valores de $\mathrm{pH}$ foram superiores para animais alimentados com sorgo conglomerado.

Os resultados de desempenho obtidos com o fornecimento de ionóforos, como a monensina e a lasalocida, para bezerras leiteiras mostram inconsistência. Stockdale et al. (1982) não observaram diferenças no ganho de peso diário comparando concentrados controle e aqueles contendo monensina ou amprolium. Da mesma forma, Foreyt et al. (1986) observaram desempenho similar de bezerros tratados com monensina, lasalocida e decoquinato, um coccidiostático não promotor de crescimento, após inoculação com Eimeria. Outros estudos conduzidos com o fornecimento de lasalocida para animais de diferentes idades, também mostram que a administração do ionóforo não afetou o desempenho de bezerros leiteiros (Waggoner et al., 1994; Nussio et al., 2002). Por outro lado, em alguns trabalhos observou-se melhor desempenho de bezerros recebendo monensina (Fitzgerald \& Mansfield, 1984; Watkins et al., 1987) ou lasalocida (Sinks et al., 1992; Quigley, 1996a). Provavelmente, parte da variação nos resultados obtidos deve-se a diferentes idades dos animais e ao fato de que animais jovens talvez não utilizem ionóforos, como animais adultos o fazem.

O objetivo deste trabalho foi avaliar as alterações do fornecimento de grãos laminado a vapor ou floculado, com ou sem a adição de monensina em parâmetros de fermentação ruminal e medidas morfométricas dos compartimentos ruminais.

\section{Material e Métodos}

Dezesseis machos holandeses foram utilizados em um experimento com delineamento em blocos ao acaso e arranjo fatorial $2 \times 2$. O experimento foi conduzido no Departamento de Produção Animal da Escola Superior de Agricultura "Luiz de Queiroz", da Universidade de São Paulo, em Piracicaba, SP.

Os bezerros foram submetidos à cirurgia para colocação de cânula ruminal de látex com orifício de $6 \mathrm{~cm}$, entre 3 e 5 dias após o nascimento. Com a recuperação pós-cirúrgica os animais foram alocados em abrigos individuais, o que permitiu o monitoramento diário do consumo de concentrado e semanal do consumo de feno. Os animais receberam $4 \mathrm{~L}$ de leite por dia, divididos em duas refeições (7 e $18 \mathrm{~h}$ ), além de água à vontade e de uma mistura concentrada. A

R. Bras. Zootec., v.32, n.4, p.1021-1031, 2003 
mistura foi fornecida ad libitum diariamente, após a retirada da sobra do dia anterior, até que o consumo atingisse $2 \mathrm{~kg} / \mathrm{d}$. O feno de coastcross passou a ser fornecimento ad libitum, após a desmama dos animais, a qual ocorreu na $8^{a}$ semana de vida.

O concentrado foi formulado para atender as exigências nutricionais de bezerros até 12 semanas de vida (NRC, 1989), sendo apresentado na Tabela 1 juntamente com a composição do feno fornecido. A concentração de monensina no concentrado foi de 30 ppm, ou $30 \mathrm{mg} \mathrm{kg}^{-1}$ de matéria seca, dose mais utilizada por produtores por ser recomendada para o controle de coccidiose em bezerros leiteiros.

Os animais foram pesados ao nascer e a cada semana até completarem 10 semanas de vida, quando se encerrou o período experimental.

Amostras de concentrado e feno fornecidos foram coletadas a cada nova mistura, secas a $55^{\circ} \mathrm{C}$ e moídas a $1 \mathrm{~mm}$, para determinação de MS e proteína bruta (PB), de acordo com AOAC (1990), fibra em detergente neutro (FDN) e fibra em detergente ácido (FDA), pelo método descrito por Van Soest (1991), e amido, conforme descrito por Poore et al. (1989).
Amostras de conteúdo ruminal foram coletadas a cada 7 dias nos horários $0,2,4,8$ e $12 \mathrm{~h}$ após a alimentação da manhã, até o final do experimento. Nas primeiras semanas de vida dos bezerros, a coleta foi realizada com o auxílio de uma seringa provida de tubo de silicone. A partir de aproximadamente 3 semanas de vida do bezerro, utilizou-se apenas um tubo plástico para a realização da coleta. As amostras, de aproximadamente $50 \mathrm{~mL}$, tiveram o $\mathrm{pH}$ determinado imediatamente após a coleta, por meio de potenciômetro (DMPH-2, Digimed, $\mathrm{Br}$ ), sendo armazenadas em seguida a $-10^{\circ} \mathrm{C}$ para posterior análise de ácidos graxos voláteis e amônia.

A determinação de amônia ruminal foi realizada segundo método de Chaney \& Marbach (1962) adaptado leitura em Leitor de Microplaca (BIO-RAD, Hercules, CA, EUA) utilizando-se filtro para absorbância de $550 \mathrm{~nm}$. As concentrações de ácidos graxos voláteis foram determinadas de acordo com Palmiquist \& Conrad (1971) em cromatógrafo líquido-gasoso (Hewlett Packard 5890 Series II GC), equipado com integrador (Hewlett Packard 3396 Series II Integrator) e injetor automático (Hewlett

Tabela 1 - Composição dos alimentos experimentais (\%MS)

Table 1 - Experimental feed composition (\%DM)

\begin{tabular}{|c|c|c|c|c|c|}
\hline $\begin{array}{l}\text { Ingredientes } \\
\text { Ingredients }\end{array}$ & $\mathrm{F}^{1}$ & FM & $\mathrm{L}$ & LM & $\begin{array}{l}\text { Feno } \\
\text { Hay }\end{array}$ \\
\hline Milho floculado & 67,5 & 67,5 & - & - & \\
\hline $\begin{array}{l}\text { Steam-flaked corn } \\
\text { Milho laminado }\end{array}$ & - & - & 67,5 & 67,5 & \\
\hline Steam-rolled corn & & & & & \\
\hline $\begin{array}{l}\text { Farelo de soja } \\
\text { Soybean meal }\end{array}$ & 20,0 & 20,0 & 20,0 & 20,0 & \\
\hline $\begin{array}{l}\text { Melaço } \\
\text { Molasses }\end{array}$ & 10,0 & 10,0 & 10,0 & 10,0 & \\
\hline $\begin{array}{l}\text { Premix } 1 \\
\text { Premix } 1\end{array}$ & 2,5 & - & 2,5 & - & \\
\hline $\begin{array}{l}\text { Premix } 2 \text { (com monensina) } \\
\text { Premix } 2 \text { (with monensin) }\end{array}$ & - & 2,5 & - & 2,5 & \\
\hline $\begin{array}{l}\% \text { Matéria seca } \\
\% \text { Dry matter }\end{array}$ & 95,61 & 95,86 & 95,46 & 95,85 & 95,51 \\
\hline $\begin{array}{l}\text { \% Proteína bruta } \\
\% \text { Crude protein }\end{array}$ & 17,74 & 17,29 & 17,26 & 18,22 & 7,62 \\
\hline $\begin{array}{l}\% \text { Amido } \\
\% \text { Starch }\end{array}$ & 50,48 & 48,91 & 49,63 & 50,22 & - \\
\hline $\begin{array}{l}\% \text { Fibra em detergente neutro } \\
\% \text { Neutral detergent fiber }\end{array}$ & 6,21 & 5,92 & 7,52 & 8,38 & 69,50 \\
\hline $\begin{array}{l}\% \text { Fibra em detergente ácido } \\
\% \text { Acid detergent fiber }\end{array}$ & 2,09 & 2,00 & 2,15 & 2,29 & 33,11 \\
\hline $\begin{array}{l}\% \text { Extrato etéreo } \\
\% \text { Ether extract }\end{array}$ & 2,43 & 2,35 & 2,35 & 2,51 & 0,77 \\
\hline
\end{tabular}

${ }^{1} \mathrm{~F}=$ milho floculado, $\mathrm{FM}=$ milho floculado + monensina, $\mathrm{L}=$ milho laminado, $\mathrm{LM}=$ milho laminado + monensina.

${ }^{1} \mathrm{~F}=$ steam-flaked corn, $F M=$ steam-flaked corn and monensin, $L=$ steam-rolled corn, $L M=$ steam-rolled corn and monensin.

R. Bras. Zootec., v.32, n.4, p.1021-1031, 2003 
Packard 6890 Series Injector).

Ao final do experimento, que ocorreu na $10^{\mathrm{a}}$ semana de vida, os animais foram pesados e em seguida abatidos. $\mathrm{O}$ abate dos animais foi realizado por meio de atordoamento e sangria, com o corte da jugular. Os animais tiveram a cavidade abdominal aberta, sendo os quatro compartimentos retirados livres de tecido adiposo omental. O conteúdo do trato foi retirado com auxílio de lavagens com água. Os compartimentos foram divididos em retículo-rúmen, omaso e abomaso. A capacidade máxima do retículorúmen foi medida com auxílio de amarrações na saída deste compartimento, sendo este cheio com água até sua máxima capacidade. O volume utilizado foi medido em proveta de vidro. Após retirada do excesso de água dos tecidos, foram tomadas medidas de peso do retículo-rúmen, do omaso, do abomaso e dos quatro compartimentos em conjunto.

Os dados apresentados de consumo de MS, peso e ganho de peso foram analisados como medidas repetidas no tempo, por intermédio do PROC MIXED do SAS (1991), utilizando-se o peso ao nascer como covariável. Os dados de parâmetros ruminais tam- bém foram analisados como medidas repetidas no tempo, a partir do PROC MIXED do SAS (1991), levando em conta os efeitos hora e semana de colheita de amostra. Medidas morfométricas do aprelho digestivo superior foram analisadas por meio do PROC GLM do SAS (1991).

\section{Resultados e Discussão}

O consumo de concentrado não foi afetado $(\mathrm{P}>0,05)$ pelo tipo de grão ou inclusão de monensina. Como pode ser observado na Tabela 2, o consumo de concentrado foi inferior ao esperado provavelmente devido ao efeito da cirurgia para implantação das cânulas ruminais. $O$ consumo na oitava semana, quando ocorreu a desmama, esteve abaixo do recomendado por Quigley (1996b), para garantir parcial desenvolvimento ruminal e a realização da desmama sem resultar em redução de desempenho.

O consumo de feno (Tabela 3), fornecido após a desmama, também não foi afetado pelos tratamentos, mas foi superior ao consumo de concentrado, fato não esperado para esta fase da vida do animal. Este

Tabela 2 - Médias dos quadrados mínimos do consumo de concentrado (g MS/d)

Table 2 - Least square means of concentrate intake ( $g \mathrm{DM} / \mathrm{d})$

\begin{tabular}{lcccccc}
\hline $\begin{array}{l}\text { Semana } \\
\text { Week }\end{array}$ & $\mathrm{F}^{1}$ & $\mathrm{FM}$ & $\mathrm{L}$ & $\mathrm{LM}$ & $\begin{array}{c}\mathrm{EPM}^{2} \\
\text { SEM }\end{array}$ & $\begin{array}{c}\text { Média da semana } \\
\text { Mean of the week }\end{array}$ \\
\hline 2 & & & & & 103,71 & 33,19 \\
3 & 45,38 & 53,29 & 0 & 45,80 & 100,17 & 51,05 \\
4 & 38,95 & 66,87 & 17,96 & 80,42 & 100,17 & 67,51 \\
5 & 31,45 & 62,85 & 50,49 & 125,25 & 101,36 & 98,11 \\
6 & 58,98 & 75,32 & 79,50 & 178,64 & 102,17 & 105,73 \\
7 & 27,37 & 98,57 & 126,91 & 170,07 & 103,79 & 105,23 \\
8 & 58,94 & 75,34 & 102,45 & 184,17 & 104,91 & 126,77 \\
9 & 106,95 & 53,68 & 196,91 & 149,53 & 107,79 & 168,70 \\
10 & 114,71 & 70,92 & 222,66 & 266,49 & 109,71 & 200,49 \\
\hline
\end{tabular}

${ }_{1} \mathrm{~F}=$ milho floculado, $\mathrm{FM}=$ milho floculado + monensina, $\mathrm{L}=$ milho laminado, $\mathrm{LM}=$ milho laminado + monensina.

${ }^{1} F=$ steam-flaked corn, $F M=$ steam-flaked corn and monensin, $L=$ steam-rolled corn, $L M=$ steam-rolled corn and monensin.

2 Erro-padrão da média.

2 Standard error of mean.

Tabela 3 - Médias dos quadrados mínimos do consumo de feno (g MS/d) Table 3 - Least square means of hay intake ( $\mathrm{g} \mathrm{MS} / \mathrm{d}$ )

\begin{tabular}{lcccccc}
\hline $\begin{array}{l}\text { Semana } \\
\text { Week }\end{array}$ & $\mathrm{F}^{1}$ & FM & $\mathrm{L}$ & $\mathrm{LM}$ & $\begin{array}{c}\mathrm{EPM}^{2} \\
\text { SEM }\end{array}$ & $\begin{array}{c}\text { Média da semana } \\
\text { Mean of the week }\end{array}$ \\
\hline 9 & 393,73 & 24,31 & 341,80 & 445,48 & 300,86 & 301,33 \\
10 & 405,40 & 74,31 & 368,47 & 887,98 & 300,86 & 431,54 \\
\hline
\end{tabular}

${ }^{1} \mathrm{~F}=$ milho floculado, $\mathrm{FM}=$ milho floculado + monensina, $\mathrm{L}=$ milho laminado, $\mathrm{LM}=$ milho laminado + monensina.

${ }^{1} \mathrm{~F}=$ steam-flaked corn, $F M=$ steam-flaked corn and monensin, $L=$ steam-rolled corn, $L M=$ steam-rolled corn and monensin.

2 Erro-padrão da média.

2 Standard error of mean.

R. Bras. Zootec., v.32, n.4, p.1021-1031, 2003 
resultado não foi observado em experimento semelhante com fêmeas leiteiras (Nussio et al., 2003).

Como pode ser observado na Figura 1, os baixos consumos de concentrado resultaram em desempenho inferior ao recomendado em literatura (Hoffman, 1997), e perda de peso após a desmama.

Constam na Tabela 4 as médias dos quadrados mínimos de parâmetros ruminais durante todo o período experimental.

Não foram observados efeitos significativos dos tratamentos no $\mathrm{pH}$ ruminal médio. Greenwood et al. (1997) também não observaram efeito do processamento físico do concentrado para bezerros jovens nos valores de $\mathrm{pH}$ do fluido ruminal. Vários trabalhos têm demonstrado queda no $\mathrm{pH}$ ruminal com o fornecimento de grãos com alta degradabilidade ruminal, como é o caso de milho floculado para novilhas de corte e vacas leiteiras (Theurer, 1986). Beharka et al. (1998) observaram menores valores de $\mathrm{pH}$ com o fornecimento de dieta moída para bezerros em aleitamento. Quigley et al. (1992) observaram maiores valores de $\mathrm{pH}$ com o fornecimento de lasalocida para bezerros antes ou após a desmama. Os autores sugerem que este efeito se deve à inibição de bactérias ruminais nas primeiras semanas de vida, como foi observado por Anderson et al. (1988). Nagaraja et al. (1981) observaram maior pH ruminal em vacas recebendo monensina, quando tentou-se simular acidose com infusão ruminal de glicose ou milho finamente moído.

A concentração de ácidos graxos voláteis (AGV) total não foi alterada $(\mathrm{P}>0,05)$ pelos tratamentos (Tabela 4). Como consequência dos baixos níveis de consumo de concentrado, as concentrações de AGV totais foram menores que as observadas por Winter (1985), Quigley et al. (1992) e Greenwood et al. (1997). Houve tendência para efeito do processamento

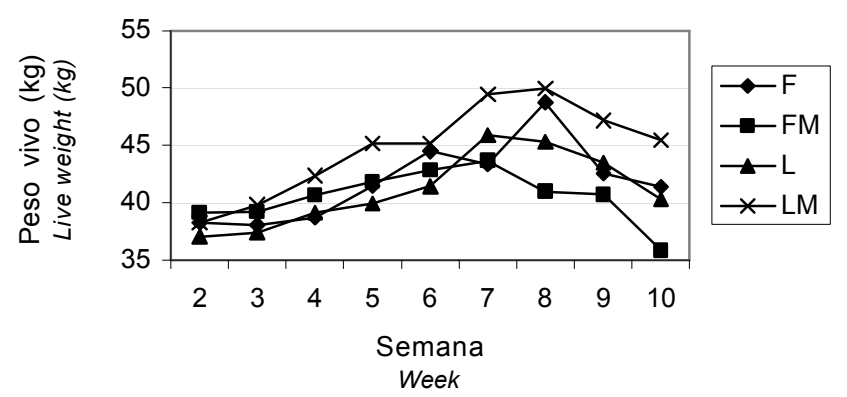

Figura 1 - Peso vivo animal (kg).

Figure 1 - Animal live weight (kg).

R. Bras. Zootec., v.32, n.4, p.1021-1031, 2003 de grãos $(P=0,11)$, sendo as concentrações molares de AGV total superiores em animais recebendo concentrado com grão laminado. Esta tendência não era esperada, uma vez que a digestibilidade ruminal de grãos floculados é superior (Theurer et al., 1999). Por outro lado, as menores proporções molares podem significar maior taxa de absorção e não menor produção de AGV (Beharka et al., 1998). Embora não tenham ocorrido diferenças no $\mathrm{pH}$ ruminal, estes dados podem indicar maior desenvolvimento do rúmen e, portanto, maior capacidade de absorção em animais recebendo grãos floculados.

Houve tendência $(P=0,12)$ para a interação entre processamento de milho e monensina na concentração molar de ácido acético (Tabela 4). Quigley et al. (1992) não observaram efeito do fornecimento de lasalocida na concentração molar deste ácido. Greenwood et al. (1997) também não observaram efeito, quando forneceram concentrado com maior ou menor nível de processamento físico. Assim, este efeito ocorreu, supostamente, devido ao maior consumo de feno observado, e não devido ao efeito da fermentação do grão na presença de monensina. A concentração de AGV no fluido ruminal é diferente para alimentos volumosos e concentrados (Owens \& Goetsch, 1988).

Contrariando as expectativas, animais alimentados com grãos floculados apresentaram menores proporções molares de ácido propiônico $(\mathrm{P}<0,05)$ (Tabela 4). Vários trabalhos demonstraram aumento na concentração de ácido propiônico com a inclusão de grão com alta digestibilidade de amido no rúmen na dieta de bovinos (Theurer et al., 1986). Esperava-se que a interação tipo de processamento de grão e inclusão de monensina resultasse em maiores proporções molares de ácido propiônico para o tratamento FM. A monensina e a lasalocida têm, reconhecidamente, o efeito de aumentar tanto a taxa de produção quanto a concentração molar de ácido propiônico (McGuffey e al., 2001). Entretanto, este efeito também não foi observado no trabalho de Quigley et al. (1992) com o fornecimento de lasalocida para bezerros antes e após a desmama.

A relação acetato:propionato não foi alterada $(\mathrm{P}>0,05)$ pelos tratamentos. De maneira geral, tanto a inclusão de monensina quanto o fornecimento de grão floculado reduzem a relação acético:propiônico, principalmente devido ao aumento na concentração de ácido propiônico (Theurer et al., 1986; McGuffey e al., 2001). Quigley et al. (1992) observaram redu- 
Tabela 4 - Médias dos quadrados mínimos de parâmetros ruminais Table 4 - Least square means of ruminal parameters

\begin{tabular}{|c|c|c|c|c|c|c|c|c|}
\hline & \multicolumn{4}{|c|}{$\begin{array}{l}\text { Tratamentos } \\
\text { Treatments }\end{array}$} & \multirow[b]{2}{*}{$\begin{array}{l}\mathrm{EPM}^{2} \\
S E M^{2}\end{array}$} & \multicolumn{3}{|c|}{$\mathrm{P}$} \\
\hline & $\mathrm{F}^{1}$ & FM & $\mathrm{L}$ & $\mathrm{LM}$ & & $\mathrm{G}^{3}$ & M & GxM \\
\hline $\mathrm{pH}$ & 6,67 & 6,86 & 6,68 & 6,73 & 0,25 & 0,81 & 0,63 & 0,79 \\
\hline AGV total, mM & 56,88 & 32,19 & 62,79 & 66,56 & 11,67 & 0,11 & 0,38 & 0,24 \\
\hline Total VFA, $m M$ & & & & & & & & \\
\hline $\begin{array}{l}\text { Ácido acético, } \mathrm{mM} \\
\text { Acetic acid, } m M\end{array}$ & 32,57 & 16,54 & 28,71 & 35,64 & 6,69 & 0,29 & 0,52 & 0,12 \\
\hline Ácido propiônico, $\mathrm{mM}$ & 16,97 & 10,47 & 25,03 & 21,66 & 4,03 & 0,03 & 0,24 & 0,70 \\
\hline $\begin{array}{l}\text { Propionic acid, } m M \\
\text { Ácido butírico, } \mathrm{mM} \\
\text { Butyric acid, } m M\end{array}$ & 4,70 & 3,04 & 5,45 & 5,57 & 1,01 & 0,13 & 0,46 & 0,39 \\
\hline $\begin{array}{l}\text { Relação acético:propiônico } \\
\text { Acetic:propionic ratio }\end{array}$ & 1,91 & 2,07 & 1,76 & 1,84 & 0,26 & 0,90 & 0,65 & 0,88 \\
\hline $\begin{array}{l}\text { Amônia, mg/dL } \\
\text { Ammonia, } m g / d L\end{array}$ & 13,85 & 8,96 & 12,99 & 12,77 & 1,53 & 0,35 & 0,12 & 0,15 \\
\hline
\end{tabular}

ção nesta relação com o fornecimento de lasalocida para bezerros em aleitamento, embora as proporções molares dos ácidos acético e propiônico não tenham sido diferentes do controle.

Houve tendência do tipo de processamento na concentração molar de ácido butírico $(\mathrm{P}=0,13)$, de forma que os animais recebendo grão laminado apresentaram os maiores valores (Tabela 4). Greenwood et al. (1997) não observaram efeito do processamento físico de concentrado na concentração molar de ácido butírico. Conforme demonstraram inúmeros trabalhos, o principal estímulo para o desenvolvimento do rúmen é a presença de AGV neste compartimento, em especial o ácido butírico (Tamate et al., 1962; Murdock \& Wallenius, 1980; Quigley et al., 1996b). A maior concentração molar deste ácido resultante do fornecimento de grãos laminados pode levar a melhor desenvolvimento ruminal e garantia de desmama adequada. Quigley et al. (1992) observaram tendência para menores proporções molares de ácido butírico em animais recebendo lasalocida, o que seria um fator limitante para a inclusão de ionóforos em concentrado de bezerros antes da desmama.

Pode-se observar tendência de inclusão de monensina $(P=0,12)$ e de interação tipo de processamento de grão e inclusão de monensina $(\mathrm{P}=0,15)$ nos níveis médios de amônia ruminal
(Tabela 4). A concentração de amônia ruminal foi reduzida com o fornecimento de monensina conforme observado em outros trabalhos (Whetstone et al., 1981; Chen \& Russell, 1991). A redução na produção de amônia está relacionada a redução na população de bactérias que deaminam aminoácidos (Yang \& Russel, 1993, citados por McGuffey et al., 2001).

Trabalhos avaliando grãos processados também observaram redução nos níveis de amônia ruminal com grão floculado, sugerindo maior síntese de proteína microbiana (Plascencia \& Zinn, 1996). No presente estudo, a floculação não reduziu a concentração ruminal de $\mathrm{N}-\mathrm{NH}_{3}$.

Foram observados efeitos significativos da idade (semana) e hora após o fornecimento de alimento em vários parâmetros ruminais, como mostram as Figuras 2 a 7.

Observou-se efeito significativo de semana de vida e hora após o fornecimento de alimento $(\mathrm{P}<0,05)$ nos valores de $\mathrm{pH}$ no fluido ruminal, como pode ser observado na Figura 2. Houve pequeno decréscimo nos valores de $\mathrm{pH}$ com o avanço da idade do animal, conforme observado por Anderson et al. (1987). Os valores de $\mathrm{pH}$ ruminal estão dentro da faixa aceitável para manutenção da saúde ruminal e fermentação adequada (Van Soest, 1994). O trabalho de Beharka et al. (1998) demonstrou redução no pH ruminal após 
a segunda semana e aumento após a décima semana de vida. Estes autores observaram alta influência da forma física do concentrado no $\mathrm{pH}$, sendo superior para animais recebendo dieta não moída, ou seja, sem processamento físico. Greenwood et al. (1997) também observaram efeito da forma física no $\mathrm{pH}$ ruminal, sendo estes valores maiores em bezerros alimentados com dieta grosseira.

Os menores valores de $\mathrm{pH}$ ruminal foram observados 2 a 4 horas após o fornecimento do alimento, assim como no trabalho de Anderson et al. (1987). Estes dados sugerem rápida fermentação ruminal e conseqüente produção de ácidos graxos voláteis.

Embora não tenha ocorrido aumento significativo no consumo de concentrado com o avanço da idade do animal, houve efeito significativo da idade do animal (semana) na concentração molar de AGV total $(\mathrm{P}<0,01)$ (Figura 3), fato também observado em outros trabalhos (Quigley et al., 1985; Anderson et al., 1987; Beharka et al., 1998). Este aumento se deve à maior capacidade de fermentação de alimentos observado com o avanço da idade de bezerros rece- bendo grãos, e conseqüente desenvolvimento ruminal. A Figura 3 também mostra o efeito significativo da interação semana e monensina $(\mathrm{P}=0,032)$.

Houve efeito significativo do horário após o fornecimento de alimento nas proporções molares de AGV $(\mathrm{P}<0,01)$, sendo os menores valores observados por volta de 4 horas após o fornecimento. Este padrão pode ter ocorrido devido a diferente taxa de absorção e metabolismo de AGV na parede ruminal, uma vez que de 2 a 4 horas foram observados menores valores de $\mathrm{pH}$ (Figura 2).

A concentração dos ácidos acético, propiônico e butírico sofreram efeitos significativos dos fatores idade do animal $(\mathrm{P}<0,01)$ e hora após o fornecimento do alimento $(\mathrm{P}<0,01)$. As proporções molares de ácido acético sofreram ainda efeitos das interações idade e tipo de processamento de grãos $(\mathrm{P}=0,048)$, idade e inclusão de monensina $(\mathrm{P}=0,025)$, e da interação tríplice idade do animal, tipo de grão e inclusão de monensina $(\mathrm{P}=0,007)$. Por outro lado, as proporções molares dos ácidos propiônico e butírico sofreram efeito da interação idade do animal e inclu-
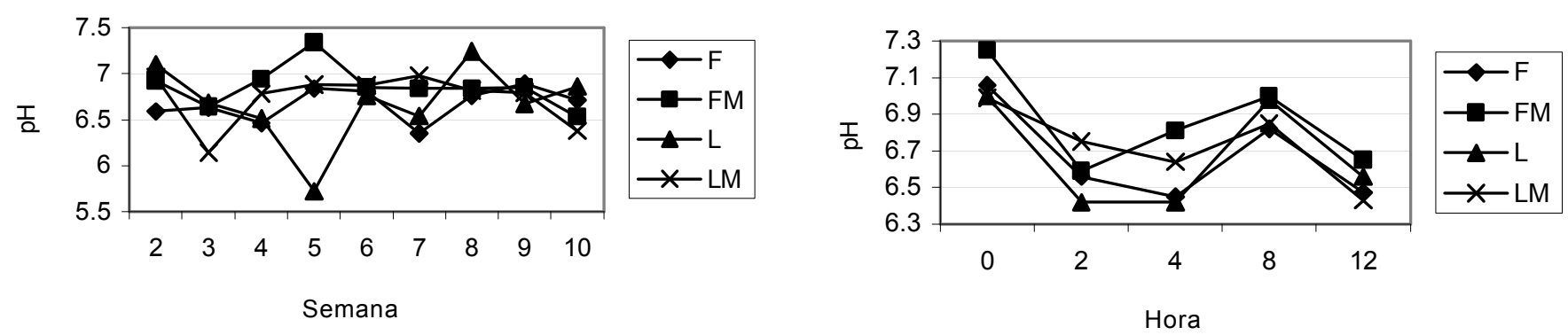

Figura 2 - Médias dos quadrados mínimos dos valores de $\mathrm{pH}$ ruminal, de acordo com a idade do animal e o horário após o fornecimento.

Figure 2 - Least square means of $\mathrm{pH}$ values, according to the animal age and time after feeding.
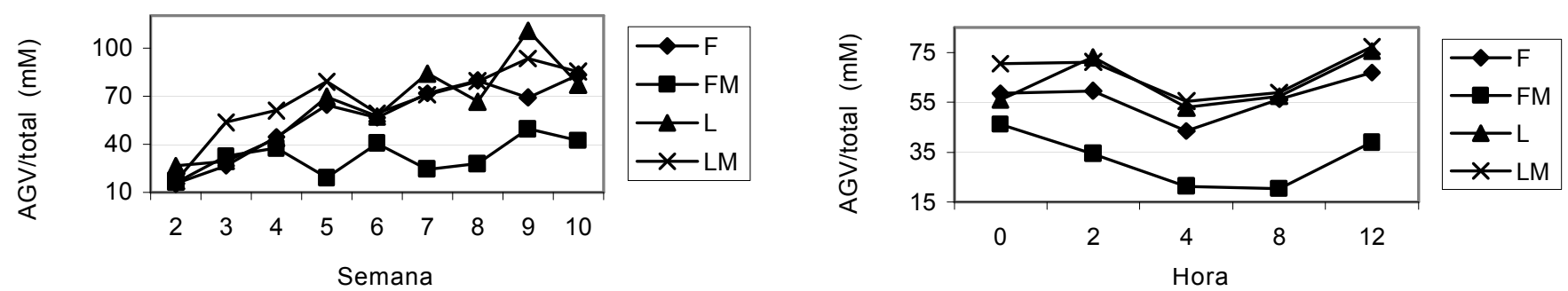

Figura 3 - Médias dos quadrados mínimos das proporções molares de ácidos graxos voláteis totais, de acordo com a idade do animal e o horário após o fornecimento.

Figure 3 - Least square means of molar proportions of total VFA, according to the animal age and time after feeding.

R. Bras. Zootec., v.32, n.4, p.1021-1031, 2003 
são de monensina $(\mathrm{P}<0,05)$.

De maneira geral, as proporções molares de cada um dos ácidos graxos voláteis foi aumentada com o avanço da idade do animal (Figuras 4, 5 e 6), demonstrando aumento na fermentação ruminal. Anderson et al. (1987b) também observaram aumento nas proporções molares dos ácidos graxos voláteis no rúmen de bezerros com o rúmen em desenvolvimento. As menores proporções molares destes ácidos foram observadas de 4 a 8 horas após o fornecimento do alimento (Figuras 4, 5 e 6), sugerindo absorção destes produtos de fermentação através da parede ruminal, uma vez que este período sucedeu ao período de menores valores de $\mathrm{pH}$.

As concentrações de amônia ruminal não foram afetados pela idade do animal, entretanto, observou-se efeito da interação idade do animal com o tipo de grão $(\mathrm{P}=0,0023)$ ou com a inclusão de monensina $(\mathrm{P}=0,0006)$, o que resultou em tendência $(\mathrm{P}<0,06)$ de efeito da interação idade do animal, tipo de grão e inclusão de monensina. As concentrações de amônia ruminal foram alteradas com a idade do animal no trabalho de Anderson et al. (1987), independentemente da idade de desmama.
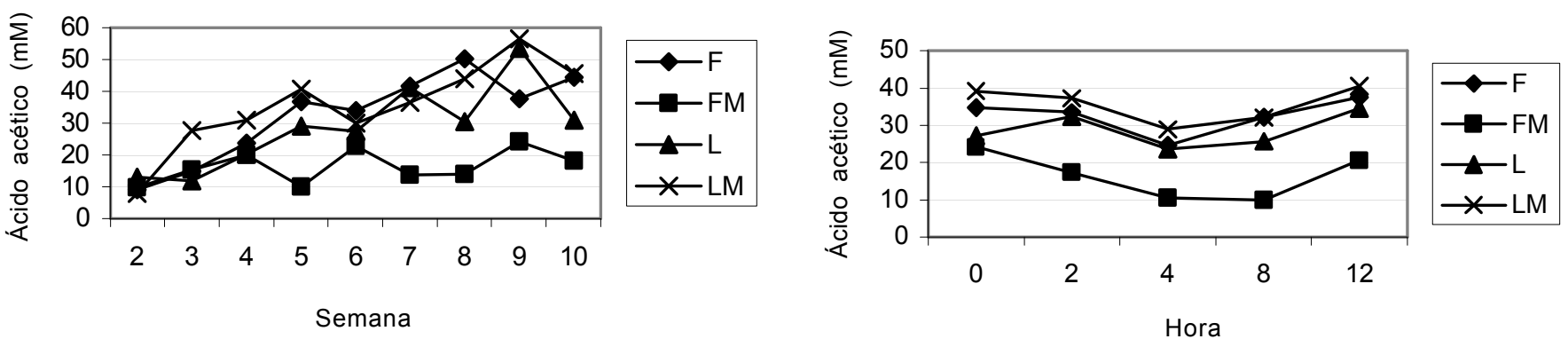

Figura 4 - Médias dos quadrados mínimos das proporções molares de ácido acético, de acordo com a idade do animal e horário após o fornecimento.

Figure 4 - Least square means of molar proportions of acetic acid, according to the animal age and time after feeding.
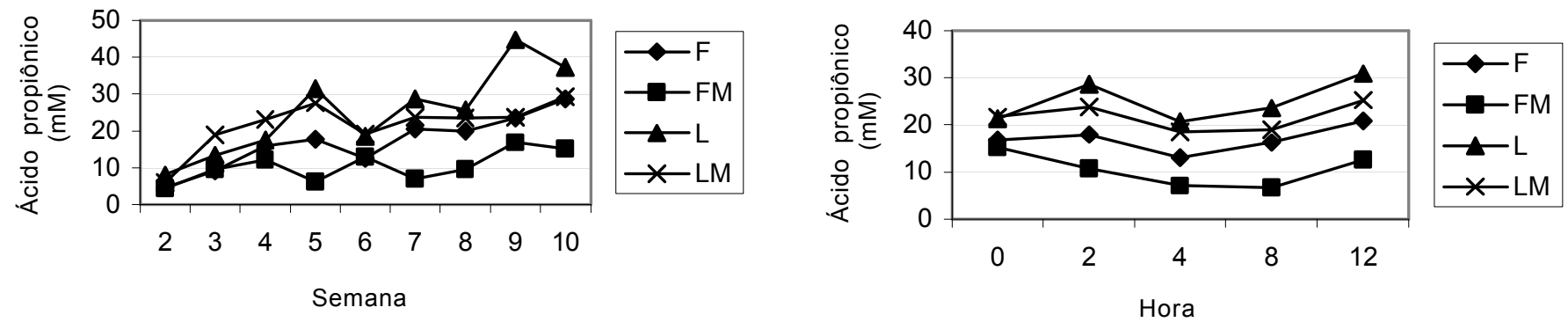

Figura 5 - Médias dos quadrados mínimos das proporções molares de ácido propiônico, de acordo com a idade do animal e o horário após o fornecimento.

Figure 5 - Least square means of molar proportions of propionic acid, according to the animal age and time after feeding.
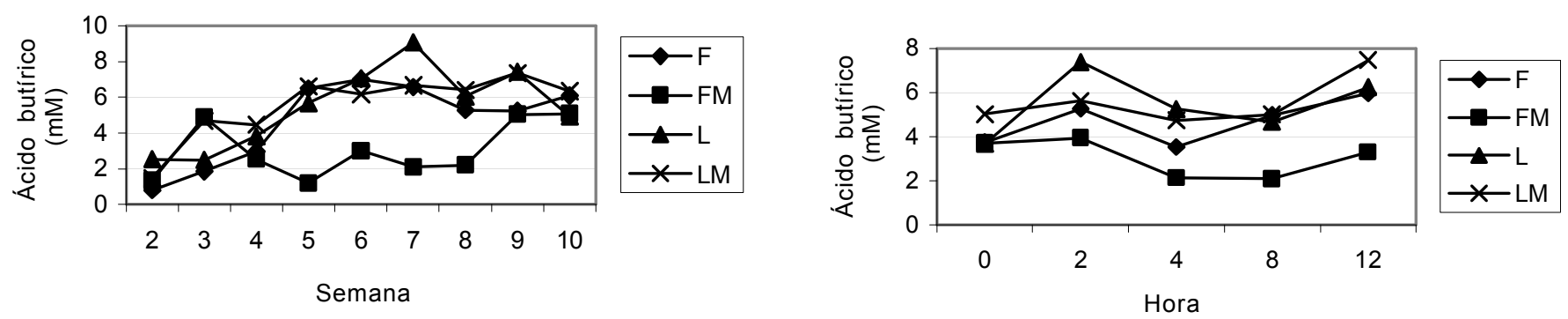

Figura 6 - Médias dos quadrados mínimos das proporções molares de ácido butírico, de acordo com a idade do animal e o horário após o fornecimento.

Figure 6 - Least square means of molar proportions of butyric acid, according to the animal age and time after feeding.

R. Bras. Zootec., v.32, n.4, p.1021-1031, 2003 

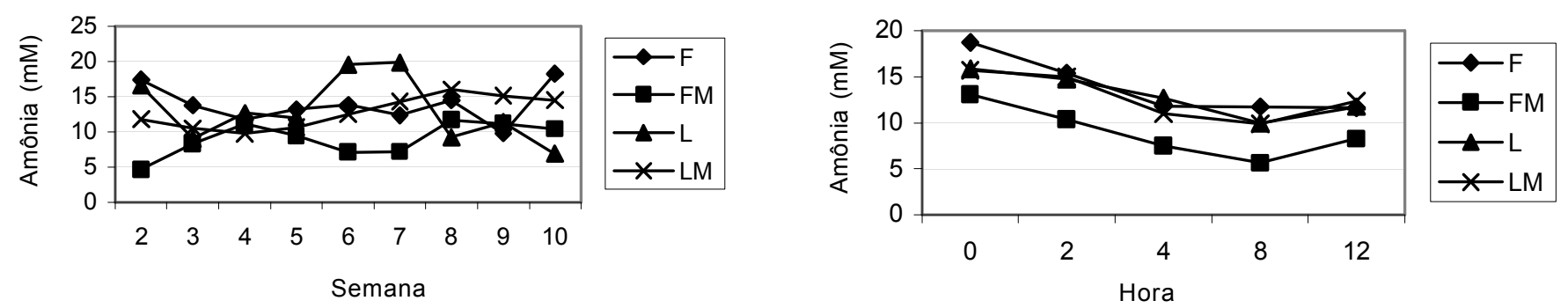

Figura 7 - Médias dos quadrados mínimos das concentrações ruminais de amônia, de acordo com a idade do animal e horário após o fornecimento.

Figure 7 - Least square means of ruminal ammonia concentrations, according to the animal age and time after feeding.

Constam na Tabela 5 os resultados das medidas de peso do trato digestivo superior e de seus quatro compartimentos.

Não houve efeito significativo do processamento de grãos, inclusão de monensina ou da interação destes dois fatores no peso do trato total, em gramas ou quando expresso em porcentagem do peso vivo do animal. Os valores observados são comparáveis aos encontrados por Tamate et al. (1962) em bezerros de 4 semanas de vida alimentados com leite, grãos e feno.

Embora o peso do retículo-rúmen também não tenha sido afetado pelos tratamentos, houve tendência de efeito do tipo de grão $(\mathrm{P}=0,11)$, da inclusão de monensina $(\mathrm{P}=0,13)$ e da interação destes fatores $(\mathrm{P}=0,09)$ no peso deste compartimento expresso como porcentagem do peso do trato total (\%TT). O fornecimento de grão laminado e de monensina resultou em maior peso $(\% \mathrm{TT})$ do retículo rúmen de bezerros. Beharka et al. (1998) não observaram efeito significativo estudando o efeito de diferente tamanho de partícula (nível de processamento) de dieta para bezerros. No trabalho de Greenwood et al. (1998) também não foram observadas diferenças significativas no peso do retículo-rúmen de bezerros alimentados com dietas com diferentes níveis de processamento físico. O maior crescimento do retículorúmen observado nos animais recebendo LM está de acordo com a tendência de maior concentração molar de ácido butírico no rúmen de animais consumindo grãos laminados (Tabela 4).

A capacidade do compartimento ruminal, medida em litros, sofreu efeito significativo da interação tipo de processamento de grão e inclusão de monensina (Tabela 5). O crescimento da camada muscular do rúmen está associado ao consumo de forragem (Lydorf Jr., 1988). Os animais recebendo concentrado com grãos floculados e monensina apresentaram menor capacidade ruminal, o que pode ser explicado pelo menor consumo de concentrado e feno, apesar destes efeitos não terem sido significativos. O maior consumo de feno observado nos animais recebendo grãos laminados e monensina resultou na maior capacidade ruminal, embora este valor não seja estatisticamente diferente dos tratamentos F e L. Tamate et al. (1962) observaram aumento na capacidade do retículo-rúmen em animais que receberam esponja plástica, muito embora estas esponjas não tenham sido encontradas nestes compartimentos no abate dos animais. Segundo os autores, este fato indica que o crescimento destes compartimentos não depende apenas da extensão mecânica da parede realizada por material compactado.

$\mathrm{O}$ peso vazio do omaso em gramas e em $\%$ do trato total não foi afetado pelo tipo de processamento de grãos, pela inclusão de monensina ou pela interação destes dois fatores. Animais recebendo dieta moída apresentaram maior peso vazio e cheio do omaso no trabalho de Beharka et al. (1998).

O peso vazio do abomaso não foi afetado pelos tratamentos. Entretanto, observou-se efeito significativo $(\mathrm{P}=0,01)$ no peso vazio expresso como porcentagem do trato total (Tabela 5). Beharka et al. (1998) não observaram efeito de processamento de dieta no peso cheio ou vazio do abomaso. Animais recebendo grãos floculados apresentaram maior peso $\%$ TT do abomaso. Ao nascer, o abomaso é o principal compartimento do estômago de um animal ruminante. A não funcionalidade do rúmen faz com que o animal dependa da digestão realizada no estômago verdadeiro do animal. Com o avanço da idade e o consumo de alimento, o rúmen começa a se desenvolver de forma que as proporções dos quatro compartimentos em relação ao trato total sofra mudanças. Um maior

R. Bras. Zootec., v.32, n.4, p.1021-1031, 2003 
Tabela 5 - Medidas métricas dos compartimentos ruminais

Table 5 - Metric means of ruminal compartiments

\begin{tabular}{|c|c|c|c|c|c|c|c|c|}
\hline & \multicolumn{4}{|c|}{$\begin{array}{c}\text { Tratamentos } \\
\text { Treatments }\end{array}$} & \multirow[b]{2}{*}{$\begin{array}{l}\mathrm{EPM}^{2} \\
S E M^{2}\end{array}$} & \multicolumn{3}{|c|}{$\mathrm{P}$} \\
\hline & $\mathrm{F}^{1}$ & $\mathrm{FM}$ & $\mathrm{L}$ & $\mathrm{LM}$ & & $\mathrm{G}^{3}$ & $\mathrm{M}$ & GxM \\
\hline Trato total, $\mathrm{g}$ & 813,33 & 708,33 & 845,00 & 1027,50 & 161,08 & 0,30 & 0,81 & 0,39 \\
\hline $\begin{array}{l}\text { Total tract, } g \\
\% \mathrm{PV} \\
\% L W\end{array}$ & 1,89 & 1,77 & 2,07 & 2,17 & 0,30 & 0,36 & 0,98 & 0,72 \\
\hline $\begin{array}{l}\text { Retículo-rúmen, } \mathrm{g} \\
\text { Reticulum-rumen,g }\end{array}$ & 503,33 & 433,33 & 520,00 & 705,00 & 116,15 & 0,24 & 0,63 & 0,29 \\
\hline $\begin{array}{l}\% \text { Trato total } \\
\% \text { Total tract }\end{array}$ & 61,43 & 61,01 & 61,20 & 67,49 & 1,80 & 0,11 & 0,13 & 0,09 \\
\hline $\begin{array}{l}\text { Capacidade, L } \\
\text { Capacity, } L\end{array}$ & 9,68 & 5,96 & 7,65 & 12,37 & 1,79 & 0,25 & 0,78 & 0,04 \\
\hline $\begin{array}{l}\text { Omaso, } \mathrm{g} \\
\text { Omasum, } \mathrm{g}\end{array}$ & 100,00 & 81,66 & 106,25 & 118,75 & 21,03 & 0,33 & 0,89 & 0,48 \\
\hline $\begin{array}{l}\% \text { Trato total } \\
\% \text { Total tract }\end{array}$ & 12,37 & 11,46 & 12,54 & 11,56 & 0,69 & 0,85 & 0,20 & 0,96 \\
\hline $\begin{array}{l}\text { Abomaso, } \mathrm{g} \\
\text { Abomasum, } g\end{array}$ & 221,66 & 195,00 & 212,50 & 210,00 & 29,42 & 0,92 & 0,63 & 0,69 \\
\hline $\begin{array}{l}\% \text { Trato total } \\
\% \text { Total tract }\end{array}$ & 27,43 & 27,88 & 25,17 & 21,62 & 1,43 & 0,01 & 0,30 & 0,19 \\
\hline
\end{tabular}

peso em \%TT do abomaso reflete menor desenvolvimento do rúmen em animais recebendo grãos floculados, ou seja, animais com menor consumo de concentrado.

As diferenças observadas nos pesos dos compartimentos do estômago do animal, refletem de maneira geral as diferenças observadas no consumo de alimento e no padrão de fermentação.

\section{Conclusões}

O processamento de milho e a inclusão de monensina na dieta não afetaram, positiva ou negativamente, parâmetros fermentativos ou medidas métricas ruminais, devido à grande variação no consumo individual de alimento, o que, provelmente pode ter sido causado por fatores de estresse pós-cirúrgico.

\section{Literatura Citada}

ABDELGADIR, I.E.O.; MORRILL, J.L. Effect of processing sorghum grain on dairy calf performance. Journal of Dairy Science, v.78, n.9, p.2040-2046, 1995.

ANDERSON, K.L.; NAGARAJA, T.G.; MORRIL, J.L. Ruminal metabolic development in calves weaned conventionally or early. Journal of Dairy Science, v.70, n.5, p.1000-1005, 1987a.

ANDERSON, K.L.; NAGARAJA, T.G.; MORRIL, J.L. et al. Ruminal microbial development in conventionally or earlyweaned calves. Journal of Animal Science, v.64, n.4, p.1215-1226, $1987 \mathrm{~b}$.

ANDERSON, K.L.; NAGARAJA, T.G.; MORRILL, J.L. et al. Performance and ruminal changes of early-weaned calves fed lasalocid. Journal of Animal Science, v.66, n.3, p.806-813, 1988.

ASSOCIATION OF OFFICIAL ANALYTIC CHEMISTS - AOAC. Official methods of analysis. 15.ed. Arlington: 1990. 473p.

BEHARKA, A.A.; NAGARAJA, T.G.; MORRILL, G.A. et al. Effects of form of the diet on anatomical, microbial, and fermentative development of the rumen of neonatal calves. Journal of Dairy Science, v.81, n.7, p.1946-1955, 1998.

CHANEY A.L.; MARBACH, E.P. Modified reagents for determination of urea and ammonia. Clinical Chemistry, v.8, n.2, p.130-132, 1962.

CHEN, G.C.; RUSSELL, J.B. Effect of monensin and a protonophore on protein degradation, peptide accumulation and deamination by mixed ruminal microorganisms in vitro. Journal of Animal Science, v.69, n.5, p.2196-2203, 1991.

DANIELS, L.B.; WINNINGHAM, R.M.; HORNSBY, Q.R. Expasion-extrusion processed sorghum grain and soybeans in diets of dairy calves. Journal of Dairy Science, v.56, n.6, p.932-934,1972.

FITZGERALD, P.R.; MANSFIELD, M.E. Control of bovine coccidiosis with monensin: in nonresistant newborn calves. American Journal of Veterinary Research, v.45, n.10, p.1984-1988, 1984.

\section{R. Bras. Zootec., v.32, n.4, p.1021-1031, 2003}


FOREYT, W.J.; RICE, D.H.; WESCOTT, R.B. Evaluation of lasalocid as a coccidiostat in calves: Titration efficacy, and comparison with monensin and decoquinate. American Journal of Veterinary Research, v. 47, n.9, p. 2031-2035, 1986.

GREENWOOD, R.H.; MORRIL, J.L.; TITGEMEYER, E.E.; et al. A new method of measuring diet abrasion and its effect on the development of the forestomach. Journal of Dairy Science, v.79, n.10, p.2534-2541, 1997.

HOFFMAN, P. Optimum body size of Holstein replacement heifers. Journal of Animal Science, v.75, n.3, p.836-845, 1997.

LYDORF JR., S.J. Growth and development of the ruminant digestive system. In: $\mathrm{CHURCH}$, D.C. The ruminant animal: digestive physiology and nutrition. Englewood Cliffs: Waveland Press, 1988. p.44-63.

McGUFFEY, R.K.; RICHARDSON, L.F.; WILKINSON, J.I.D. Ionophores for dairy cattle: current status and future outlook. Journal of Dairy Science, v. 84, n.1, p.194-203, 2001.

MURDOCK, F.R.; WALLENIUS, R.W. Fiber sources for complete calf starter rations. Journal of Dairy Science, v.63, n.11, p.1869-1873, 1980.

NAGARAJA, T.G.; AVERY, T.B.; BARTLEY, E.E. et al. Prevention of lactic acidosis in cattle by lasalocid or monensin. Journal of Animal Science, v.53, n.2, p.206-215, 1981.

NATIONAL RESEARCH COUNCIL - NRC. Nutrient requirement in dairy cattle. 6.ed. Washington: National Academy of Science, 1989. 158p.

NUSSIO, C.M.B. Processamento de milho (Floculado vs. Laminado) e adição de monensina para bezerras leiteiras, pré e pós-desmama precoce. Revista Brasileira de Zootecnia, v.32, n.1, p.229-239, 2003.

NUSSIO, C.M.B; HUBER, J.T.; NUSSIO, L.G. Decoquinate, lasalocid and monensin in starter feeds and the performance of holstein calves to 20 weeks of age. Scientia Agricola, v.59, n.3, p. 421-426, 2002.

OWENS, F.N.; GOETSCH, A.L. Ruminal fermentation. In: $\mathrm{CHURCH}$, D.C. (Ed.) The ruminant animal: digestive physiology and nutrition. Englewood Cliffs: Waveland Press, 1988. p.145-171.

PALMIQUIST, D.; CONRAD, H. Origin of plasma fatty acids in lactating cows fed high grain or high fat diets. Journal of Dairy Science, v.54, n.7, p.1025, 1971.

PLASCENCIA, A.; ZINN, R.A. Influence of flake density on the feeding value of steam-processed corn in diets for lactating cows. Journal of Animal Science, v.74, n.2, p.310-316, 1996.

POORE, M.H.; ECK, T.P.; SWINGLE, R.S.; et al. Total starch and relative starch availability of feed grain. In: BIENNAL CONFERENCE ON RUMEN FUNCTION, 20., 1989, Chicago. Proceedings... Chicago: USDA, 1989. p.23-45.

QUIGLEY III, J.D.; SCHWAB, C.G.; HYLTON, W.E. Development of rumen function in calves: Nature of protein reaching the abomasum.. Journal of Dairy Science, v.68, n.3, p.694-702, 1985.

QUIGLEY III, J.D. Effects of lasalocid in milk replacer and calf starter on growth, intake, and fecal oocyst shedding in calves challenged with Eimeria. Journal of Dairy Science, v.79, p.154, Suppl.1, 1996.

QUIGLEY III, J.D. Feeding prior to weaning. In: CALVES, HEIFERS AND DAIRY PROFITABILITY NATIONAL CONFERENCE, Pennsylvania, 1996. Proceedings ... Ithaca: Northeast Regional Agricultural Engineering Service Cooperative Extension, 1996b. p.245-255.
QUIGLEY III, J.D.; BOEHMS, S.I.; STEEN, T.M.; et al. Effects of lasalocid on selected ruminal and blood metabolites in young calves. Journal of Dairy Science, v.75, n.8, p.2235-2241, 1992.

SAS INSTITUTE. SAS users guide: Statistics, version 5. Cary: 1991. 1028p.

SCHUH, J.D.; HALE, W.H.; THEURER, C.B. Pressure cooking versus steam processing and flaking sorghum grain for dairy calves. Journal of Dairy Science, v.54, n.3, p.401-404, 1971.

SCHUH, J.D.; LIMA, J.O.A.; HALE, W.H.; THEURER, C.B. Steamprocessed flaked grains versus steam-rolled grains for dairy calves. Journal of Dairy Science, v.53, n.4, p.475-479, 1970.

SINKS, G.D., QUIGLEY III, J.D., REINEMEYER, C.R. Effects of lasalocid on coccidial infection and growth in young dairy calves. Journal of the American Veterinary Medicine Association, v.200, n.12, p.1947, 1992.

STOCKDALE, P.H.G.; SHEARD, A.; TIFFIN, G.B. Resistance to Eimeria bovis produced after chemotherapy of experimental infections in calves. Veterinary Parasitology, v.9, n.4, p.171-177, 1981.

TAMATE, H.; McGILLIARD, A.D.; JACOBSON, N.L. et al. Effect of various dietaries on the anatomical development of the stomach in the calf. Journal of Dairy Science, v.45, n.3, p.408-420, 1962.

THEURER, C.B. Grain processing effects on starch utilization by ruminants. Journal of Animal Science, v.63, n.5, p.1649-1662, 1986.

THEURER, C.B.; J.T.HUBER; DELGADO-ELOURDY, A. Steam flaking improves starch utilization and milk production parameters. In: CORNELL NUTRITION CONFERENCE FOR FEED MANUFACTURES, Rochester, 1996. Proceedings... Rochester: Cornell University, 1996. p.121-130.

THEURER, C.B.; HUBER, J.T.; DELGADO-ELORDUY, A.; et al. Invited review: Summary of steam-flaking corn or sorghum grain for lactating dairy cows. Journal of Dairy Science, v.82, n.9, p.1950-1959, 1999.

Van SOEST, P.J. Nutritional ecology of the ruminant. Ithaca: Cornell University Press, 1994. 476p.

Van SOEST, P.J.; ROBERTSON, J.B.; LEWIS, B.A. Methods for dietary fiber neutral detergent fiber, and non-starch polysaccharides in relation to animal nutrition. Journal of Dairy Science, v.74, n.10, p.3583-3597, 1991.

WAGGONER, J.K.; CECAVA, M.J.; KAZACOS, K.R. Efficacy of lasalocid and decoquinate against coccidiosis in naturally infected dairy calves. Journal of Dairy Science, v.77, n.1, p.349-353, 1994.

WATKINS, L.E.; WRAY, M.I.; BASSON, R.P. et al. The prophylactic effects of monensin fed to cattle inoculated with coccidia oocysts. Agri-Practice, v.7, n.6, p.18-20, 1987.

WINTER, K.A. Comparative performance and digestibility in dairy calves weaned at three, five, and seven weeks of age. Canadian Journal of Animal Science, v.65, n.2, p.445-450, 1985. 